\title{
Vigencia y desplazamiento de la lengua aymara en Chile
}

\author{
Currency and Displacement of the Aymara Language in Chile \\ Hans Gundermann ${ }^{1}$, Héctor González $z^{2}$, Jorge Iván Vergara ${ }^{3}$ \\ ${ }^{1}$ Instituto de Investigaciones Arqueológicas y Museo R.P. Gustavo Le Paige S.J., \\ Universidad Católica del Norte, San Pedro de Atacama, Chile. \\ e-mail: hgunder@ucn.cl. \\ ${ }^{2}$ Departamento de Antropología; Centro de Investigaciones del Hombre en el Desierto, \\ Universidad de Tarapacá, Arica, Chile. \\ ${ }^{3}$ Departamento de Ciencias Sociales, Universidad Arturo Prat, Iquique, Chile.
}

\begin{abstract}
El artículo examina la situación actual de la lengua aymara en la Región de Tarapacá, el territorio tradicional de localización de este pueblo en Chile. El objetivo principal es caracterizar su vigencia y las características que asume su desplazamiento por el castellano, la lengua regional dominante. Para ello, se revisan los actuales niveles de competencia, las condiciones, contextos de uso y aprendizaje, tanto del aymara como del castellano. Finalmente, se discuten las dinámicas de continuidad y cambio sociolingüístico.
\end{abstract}

Palabras clave: Tarapacá, Chile, lengua aymara, caracterización sociolingüística.

This paper examines the present situation of the Aymara language in Tarapacá (Region I), the traditional territory inhabited by a group of indigenous people in Chile. The main objective here is to analyze the usage, knowledge and the characteristics of the gradual displacement of the Aymara language by Spanish, the dominant local language. The current levels of competence, conditions and contexts of usage and learning, both of the Aymara and Spanish languages are described. Finally, the dynamics of continuity and sociolinguistic change are discussed.

Key words: Tarapacá, Chile, aymara language, sociolinguistic characterization.

\section{INTRODUCCIÓN}

Este artículo pretende aportar a la comprensión de la situación actual del aymara, la principal lengua indígena del norte de Chile y la segunda en importancia a nivel nacional, después del mapudungun. Los trabajos sobre esta lengua son poco numerosos y están mayormente dedicados a la descripción de su estructura interna, aunque en las últimas dos décadas se han realizado varios estudios sociolingüísticos basados en procedimientos de encuesta social. Nuestro trabajo aspira a actualizar los datos disponibles (la última investigación de este tipo fue realizada hace más de diez años); aportar antecedentes sobre temáticas no consideradas anteriormente; incorporar información etnográfica para enriquecer el análisis estadístico; y, en base a lo anterior, proponer una interpretación preliminar acerca de la relación entre la situación de su lengua y determinados procesos de cambio que afectan al conjunto del pueblo aymara en Chile. La relevancia de la temática no necesita ser subrayada: el estado actual de esta lengua indígena y sus tendencias de desarrollo a futuro constituyen una materia de preocupación para la institucionalidad pública, el mundo académico y los propios aymaras, sus dirigentes y organizaciones. A estos efectos, nos concentraremos en dos aspectos sociolingüísticos centrales: la vigencia en el uso del aymara y su desplazamiento por el castellano. Para ello, describiremos la distribución de hablantes en las comunidades estudiadas, sus niveles de competencia en lengua aymara y sus condiciones de aprendizaje, uso y contexto.

Los antecedentes provienen de una investigación llevada a cabo para el Programa de Educación Intercultural Bilingüe (PEIB) del Ministerio de Educación, que consideró a los pueblos aymara, atacameño y mapuche ${ }^{1}$. La interpretación aquí presentada es nueva y de exclusiva responsabilidad de los autores de este trabajo. Trataremos sólo lo relativo a la población aymara en la Región de Tarapacá, específicamente las comunas de General Lagos y Putre, en la provincia de Parinacota; y Huara, Camiña,

\footnotetext{
${ }^{1}$ El estudio fue realizado por el Instituto de Estudios Andinos de la Universidad Arturo Prat para el Programa de EIB del Ministerio de Educación/Orígenes entre los años 2002 y 2003. Los resultados referentes al total de pueblos y regiones comprendidos pueden verse en: Vergara, Gundermann et al. (2005).
} 
Colchane, Pica y Pozo Almonte, en la de Iquique. Por diversas razones, asociadas a los objetivos del estudio señalado, no se consideraron ni la comuna de Camarones ni los valles de Lluta y Azapa de la comuna de Arica.

\section{MATERIAL Y MÉTODO}

La información se obtuvo a través de una encuesta aplicada a una muestra representativa de la población rural de 18 o más años que, de acuerdo al Censo del año 2002, existía en las comunas mencionadas $^{2}$. Se incluyó la población total, indígena y no indígena, puesto que por tratarse de una muestra aleatoria, ambos segmentos deberían tener la misma probabilidad de ser seleccionados al momento del sorteo en relación a sus parámetros. Se consideró solamente a los individuos de 18 y más años de edad, por cuanto podían dar mejor cuenta de su acervo sociolingüístico, tener una mayor conciencia acerca de la competencia linguiística y entregar, en general, información de mejor calidad. Asimismo, dado que el sistema de entrevistas operaría en base al sujeto del hogar sorteado (que recibiera al encuestador o tuviese la disposición de contestar), no aseguraba una proporción de casos por sexo cercana a los parámetros, se establecieron cuotas para hombres y mujeres, utilizando el índice de masculinidad existente en cada comuna, considerando solamente las viviendas particulares.

Se trabajó con una muestra con un margen de error de un 5\%, hipótesis de varianzas del 50\% y un nivel de confianza de 2 sigmas, esto es del 95,5\%. Para el cálculo de las muestras se utilizó una fórmula de uso corriente para universos finitos. Aunque el total de la muestra regional se distribuyó de manera proporcional entre las comunas de acuerdo al peso poblacional de ellas, se aumentaron los casos a 30 en todas aquellas que mediante este procedimiento la cuota resultante fuese inferior a este número, de manera que tuviesen la cantidad mínima de casos que permitiese validez en los análisis estadísticos.

Para la ubicación geográfica de la base muestral y la localización específica de los casos considerados en la muestra, se utilizó la información censal y cartográfica del Instituto Nacional de Estadísticas. Para ello se numeraron los individuos existentes en cada comuna, ubicándolos en el agregado mínimo censal, que corresponde al sector (una mitad de manzana en sectores urbanos o nucleados y viviendas o grupo de viviendas aisladas en sectores de residencia dispersa). Dado que el Censo 2002 aún no estaba disponible con estos niveles de desagregación, el procedimiento se realizó a través de la base censal del Censo 1992 de cada región, utilizando el sistema REDATAM. Se tuvo en consideración, además, que en los sectores rurales las variaciones de población son generalmente menores y normalmente se pueden corregir en terreno, agregando los sectores y viviendas que haya lugar.

El sorteo se realizó mediante un programa especial de selección de números aleatorios. Aparte de los casos correspondientes por muestra, se sortearon también reemplazos. Para identificar los casos en terreno, se establecieron hojas de ruta con el orden de encuestaje, acompañadas de la cartografía correspondiente para ubicar y sortear viviendas (agregando las variaciones que pudiese haber del Censo de 1992 a la fecha), de acuerdo a los casos correspondientes al sector con individuos sorteados.

Finalmente, la información de las encuestas fue codificada y traspasada a una base de datos, para ser trabajada con el programa SPSS (Statistical Package For Social Sciences). Para el análisis de la información, aparte de la variable comuna, se utilizó también una variable geográfica referida a los distintos pisos ecológicos existentes en el sector rural regional: altiplano, valles altos o precordilleranos, y valles bajos y oasis. Aparte de que estos sectores geográficos determinan distintas especializaciones productivas agropecuarias para el pueblo aymara, se sabe que también han implicado diferentes conexiones con la economía y la sociedad regional.

\section{PUEBLOS INDÍGENAS Y LENGUA AYMARA EN EL NORTE DE CHILE}

3.1. La lengua aymara de Chile en el contexto subregional. El pueblo aymara se extiende por una extensa área que comprende las tierras altas de Bolivia, el sur de Perú y el norte de Chile, alcanzando a unos tres millones de personas, dos tercios de las cuales serían hablantes de su lengua nativa. La mayor parte se ubicaría en el occidente boliviano (1,7 millones de hablantes), en las regiones peruanas colindantes con el lago Titicaca (0,5 millón de hablantes) y el norte de Chile (unos 20.000 hablantes)

\footnotetext{
${ }^{2}$ Debido a que existían escuelas atendidas por este programa, también se incluyeron las localidades de Putre y Pica, que son consideradas como centros urbanos en la clasificación censal.
} 
(Albó 2000: 44). Esta lengua vive actualmente un proceso de redistribución y ampliación geográfica producto de las intensas migraciones desde los sectores tradicionales de asentamiento a las ciudades costeras y regiones de colonización, lo que se ha acompañado de un aumento de las presiones de desplazamiento y pérdida del uso, cuestiones que no han sido tomadas en cuenta en los estudios generales sobre su situación lingüística y etnográfica (Danemann y Valencia 1989; Salas 1996). En nuestro país, la población aymara se concentra en la Región de Tarapacá con 40.700 individuos, correspondientes a un $83,9 \%$ del total nacional (INE 2002). La mayor parte $(79,3 \%$ ) habita en los sectores urbanos de la región, en las comunas de Arica e Iquique. Con respecto al número de hablantes de aymara no se cuenta con información estadística. Un estudio realizado en los años ochenta estimó en 14.934 su número, de un total de 33.546 personas aymaras, o sea, cerca de un 45\% del total (Gundermann 1994). El estudio actual indica, por el contrario, que dicho porcentaje no sería superior al 35\%. Con todo, no es posible hacer estimaciones más confiables si no se aborda la realidad urbana y no sólo el ámbito rural tradicional, lo que debiera ser materia de futuras investigaciones.

3.2. Población y adscripción étnica en las localidades estudiadas. Las comunidades estudiadas se concentran en el llamado espacio andino histórico de la Región de Tarapacá, esto es, las zonas de la precordillera y altiplano, donde la población aymara es mayoritaria, a diferencia de las zonas de valles bajos u oasis, donde los no indígenas aumentan progresivamente en número, reemplazando casi totalmente a los indígenas. El asentamiento de la población marca, aunque no la determina del todo, hasta hoy la distribución de las prácticas culturales indígenas.

Tabla 1

Distribución de la población de las comunas en estudio por sector geográfico según adscripción étnica

\begin{tabular}{|c|c|c|c|c|c|c|c|c|c|c|c|c|}
\hline \multirow{3}{*}{ Sector Geográfico } & \multicolumn{10}{|c|}{ Identidad Etnica } & \multirow{2}{*}{\multicolumn{2}{|c|}{ Total }} \\
\hline & \multicolumn{2}{|c|}{ Aymara } & \multicolumn{2}{|c|}{ Quechua } & \multicolumn{2}{|c|}{ Otra Etnia } & \multicolumn{2}{|c|}{ NS/NR } & \multicolumn{2}{|c|}{ No Indígena } & & \\
\hline & $\mathrm{N}^{\circ}$ & $\%$ & $\mathrm{~N}^{\mathrm{o}}$ & $\%$ & $\mathrm{~N}^{\circ}$ & $\%$ & $\mathrm{~N}^{\circ}$ & $\%$ & $\mathrm{~N}^{\mathrm{o}}$ & $\%$ & $\mathrm{~N}^{\mathrm{o}}$ & $\%$ \\
\hline Altiplano & 62 & 89,9 & 0 & 0,0 & 0 & 0,0 & 0 & 0,0 & 7 & 10,1 & 69 & 17,1 \\
\hline Precordillera & 62 & 58,5 & 12 & 11,3 & 0 & 0,0 & 3 & 2,8 & 29 & 27,4 & 106 & 26,3 \\
\hline $\begin{array}{l}\text { Valle } \\
\text { Bajo/Oasis }\end{array}$ & 46 & 29,1 & 6 & 3,8 & 2 & 1,3 & 4 & 2,5 & 100 & 63,3 & 158 & 39,2 \\
\hline Pampa & 11 & 16,4 & 0 & 0,0 & 4 & 6,0 & 3 & 4,5 & 49 & 73,1 & 67 & 16,6 \\
\hline Costa & 0 & 0,0 & 0 & 0,0 & 0 & 0,0 & 0 & 0,0 & 3 & 100,0 & 3 & 0,7 \\
\hline Total & 181 & 44,9 & 18 & 4,5 & 6 & 1,5 & 10 & 2,5 & 188 & 46,7 & 403 & 100,0 \\
\hline
\end{tabular}

Fuente: Encuesta Contexto Sociolingüístico de Comunidades Escolares Indígenas, 2003.

Los resultados del estudio confirman la alta presencia aymara en toda el área en estudio, aunque con importantes variaciones internas, de acuerdo al sector geográfico de que se trate. En general, la población que se identifica como aymara desciende en un eje longitudinal a medida que se baja desde los sectores más altos hacia los más bajos. Es claramente mayoritaria en el altiplano (89,9\%), que corresponde a las comunas de General Lagos y Colchane en su totalidad y parte de Putre y Pica. En la zona de precordillera que abarca la totalidad de la comuna de Camiña y parte de la de Putre, Huara y Pozo Almonte la identificación sigue siendo relativamente importante, aunque desciende a un 58,5\%. En la zona de Valles Bajos y Oasis (que abarca toda la comuna de Pica y parte de la de Huara), la adscripción aymara sólo llega a un $29,1 \%$, mientras que en el sector de la Pampa (que incluye parte de las comunas de Huara y Pozo Almonte) es sólo de un 16,4\%.

La presencia de población quechua merece una explicación. En la mayoría de los casos no se trata de 
migrantes o miembros originarios de esta etnia, sino de habitantes de algunas comunidades de la precordillera (como Mamiña, en Pozo Almonte) y de valles bajos (como Miñe-Miñe, en Huara, y Pica, en la comuna homónima), que se autoadscriben como quechuas para diferenciarse de los migrantes aymaras instalados en sus localidades. Los casos de representantes de otros pueblos indígenas son muy pocos. Se trata de migrantes mapuches, o bien de lo que se conoce como autoadscripciones sin base biográfica, identificaciones de solidaridad o de "tribalidad", cuya extracción es más bien urbana (Gundermann, Foerster y Vergara 2005).

3.3. Los hablantes de lenguas indígenas y castellano. La mayor parte de la población total del área estudiada (un 64,5\%) declara no tener competencia lingüística en ninguna lengua indígena ${ }^{3}$. Si se consideran solamente las personas que se autodefinen aymaras, un 65,7\% (119 casos) señala poseer alguna competencia general en su lengua. Como es predecible, existen visibles diferencias según los sectores geográficos. Mientras en el altiplano dicha competencia llega a un 95,2\%, en la precordillera es de un $61,2 \%$, y en la zona de valles bajos, oasis y pampa alcanza sólo a un 38,6\%.

Tabla 2

Declaraciones de competencia en lenguas indígenas según sector geográfico

\begin{tabular}{|c|c|c|c|c|c|c|c|}
\hline \multirow{3}{*}{ Sector Geográfico } & \multicolumn{4}{|c|}{ Competencia lingüística } & \multirow{2}{*}{\multicolumn{2}{|c|}{ Total }} & \multirow{3}{*}{$\begin{array}{c}\text { Adscripción } \\
\text { aymara }\end{array}$} \\
\hline & \multicolumn{2}{|c|}{ Sí } & \multicolumn{2}{|c|}{ No } & & & \\
\hline & $\mathrm{N}^{\mathrm{o}}$ & $\%$ & $\mathrm{~N}^{\mathrm{o}}$ & $\%$ & $\mathrm{~N}^{\mathrm{o}}$ & $\%$ & \\
\hline Altiplano & 59 & 95,2 & 3 & 4,8 & 62 & 34,3 & 89,9 \\
\hline Precordillera & 38 & 61,3 & 24 & 38,7 & 62 & 34,3 & 58,5 \\
\hline Valle Bajo, Oasis y Pampa & 22 & 38,6 & 35 & 61,4 & 57 & 31,5 & 25,3 \\
\hline Total & 119 & 65,7 & 62 & 34,3 & 181 & 100,0 & 44,9 \\
\hline
\end{tabular}

Fuente: Encuesta contexto sociolingüístico de comunidades escolares indígenas, 2003

Lo mismo que la autoadscripción, la competencia en lengua aymara desciende en dirección a los sectores más bajos, lo que muestra que la heterogeneidad étnica interna del área en estudio también se manifiesta a nivel lingüístico.

Tabla 3

Competencia pasiva en lengua indígena en la I Región según sectores ecológicos

\begin{tabular}{|l|l|l|}
\hline Sector Geográfico & Grado de Competencia Pasiva: Lengua Indígena & Total \\
\hline
\end{tabular}

\footnotetext{
${ }^{3}$ Utilizamos la noción de competencia en un sentido algo más amplio que Hymes (1988). Convergen en ella dos componentes. El primero es el conocimiento de un léxico, y de reglas y convenciones (sintácticas y gramaticales) indispensables para la comunicación. En situaciones sociohistóricas de pérdida acelerada de una lengua o de reaprendizaje incipiente, como ocurre hoy con las lenguas indígenas de Chile, la variación de este conocimiento puede ser muy amplia: desde un vocabulario restringido hasta una capacidad de desempeño conspicua. El otro componente es el desempeño, que incluye la idea de actuación, correspondiente con los modos y oportunidades de uso de léxico, recursos gramaticales, elementos paralingüísticos, etc. Pero el desempeño también se refiere a algo más genérico: lo que logra hacer comunicativamente un individuo, un grupo o una categoría social a partir de los conocimientos de que dispone. Por las características del estudio y el tamaño de la muestra, se tomó como base la declaración de competencia, no siendo posible cotejar los datos a partir de una medición de competencia utilizando un instrumento linguiístico ad hoc.
} 


\begin{tabular}{|l|c|c|c|c|c|c|c|c|}
\hline & \multicolumn{2}{|c|}{ Mucho } & \multicolumn{2}{c|}{ Bastante } & \multicolumn{2}{c|}{ Poco } & \multicolumn{2}{c|}{} \\
\cline { 2 - 11 } & $N^{\circ}$ & $\%$ & $N^{\circ}$ & $\%$ & $N^{\circ}$ & $\%$ & $N^{\circ}$ & $\%$ \\
\hline Altiplano & 40 & 64,5 & 14 & 22,6 & 8 & 12,9 & 62 & 45,6 \\
\hline Precordillera & 17 & 38,6 & 9 & 20,5 & 18 & 40,9 & 44 & 32,4 \\
\hline Valle Bajo/Oasis/Pampa & 10 & 33,3 & 10 & 33,3 & 10 & 33,3 & 30 & 22,1 \\
\hline Total & 67 & 49,3 & 33 & 24,3 & 36 & 26,5 & 136 & 100,0 \\
\hline
\end{tabular}

Fuente: Encuesta contexto sociolingüístico de comunidades escolares indígenas, 2003.

Establecer el grado de competencia activa y pasiva en la lengua puede ayudar a interpretar mejor los resultados presentados. De las personas que declaran tener competencia general en aymara, un 49,3\% afirma tener una competencia pasiva alta ("mucho"), y un $24,3 \%$ se ubica en la categoría intermedia de "bastante". Los casos con baja comprensión ("poco") representan sólo un 26,5\%.

Tabla 4

Competencia activa en lengua indígena según sectores ecológicos

\begin{tabular}{|c|c|c|c|c|c|c|c|c|c|c|}
\hline \multirow{3}{*}{ Sector Geográfico } & \multicolumn{8}{|c|}{ Grado de Competencia Activa: Lengua Indígena } & \multirow{2}{*}{\multicolumn{2}{|c|}{ Total }} \\
\hline & \multicolumn{2}{|c|}{ Muy bien } & \multicolumn{2}{|c|}{ Bien } & \multicolumn{2}{|c|}{ Poco } & \multicolumn{2}{|c|}{ Nada } & & \\
\hline & $\mathrm{N}^{\mathrm{o}}$ & $\%$ & $\mathrm{~N}^{\mathrm{o}}$ & $\%$ & $\mathrm{~N}^{\mathrm{o}}$ & $\%$ & $\mathrm{~N}^{\mathrm{o}}$ & $\%$ & $\mathrm{~N}^{\mathrm{o}}$ & $\%$ \\
\hline Altiplano & 27 & 43,5 & 17 & 27,4 & 17 & 27,4 & 1 & 1,6 & 62 & 45,6 \\
\hline Precordillera & 10 & 22,7 & 4 & 9,1 & 25 & 56,8 & 5 & 11,4 & 44 & 32,4 \\
\hline $\begin{array}{l}\text { Valle } \\
\text { Bajo/Oasis/Pampa }\end{array}$ & 5 & 16,7 & 7 & 23,3 & 16 & 53,3 & 2 & 6,7 & 30 & 22,1 \\
\hline Total & 42 & 30,9 & 28 & 20,6 & 58 & 42,6 & 8 & 5,9 & 136 & 100,0 \\
\hline
\end{tabular}

Fuente: Encuesta contexto sociolingüístico de comunidades escolares indígenas, 2003.

Un juicio más fundado se puede alcanzar con la revisión de la competencia activa. Poco más de la mitad de los casos (un 51,5\%) declara tener competencia activa en lengua aymara en los grados de "Muy Bien" y "Bien". Los restantes son hablantes que pueden desenvolverse activamente con dificultades (un $42,6 \%$ se ubica en la categoría de "Poco"), o, simplemente, individuos que entienden algo de aymara pero no poseen capacidad alguna para hablarlo (un 5,9\% que declara "Nada").

Si se considera a las personas que se identifican como aymaras más las que no lo hacen pero declaran tener competencia en aymara (lo que suma un total de 198 casos), los hablantes eficientes de la lengua representarían un 35,2\% del total. Cabe recordar también que los entrevistados fueron hombres y mujeres de 18 años de edad y más. Según estos datos, y atendiendo a lo dicho más arriba respecto al autorreconocimiento indígena en la región, las proporciones encontradas no pueden extenderse al 
conjunto de la población aymara. Con toda probabilidad encontraremos en ésta porcentajes inferiores de hablantes.

La situación de conocimiento y competencia lingüística en aymara se puede observar también desde una perspectiva más amplia, tomando en cuenta los datos sobre competencia en castellano, la lengua prevaleciente. Si se considera a los individuos que manifiestan tener competencia en la lengua aymara (133 casos válidos), un porcentaje bastante alto $(87,2 \%)$ declara una competencia solvente en castellano (en los registros de "Muy Bien" y "Bien"). Los casos de baja competencia representan sólo un 12,8\% (correspondientes a la categoría "Poco"). El elevado porcentaje de eficiencia en castellano contrasta con la mucho menor proporción $(35,2 \%)$ de personas que aseguran tener un manejo comparable ("Muy Bien" y "Bien") en lengua aymara. La situación es todavía más preocupante si se considera que aproximadamente un tercio del total de quienes se identifican como aymaras son monolingües del castellano (62 personas).

El monolingüismo castellano está considerablemente extendido en las comunidades aymaras; de manera inversa, parece haber desaparecido completamente el monolingüismo aymara. En el otro extremo del registro de edad, los entrevistados convergen para señalar que sólo pocos niños son bilingües; es decir, tienen competencia -variable- en lengua indígena y castellano. Según los contextos comunitarios de que se trate, un grupo no despreciable de personas declara que ya no hay niños bilingües en sus comunidades. En efecto, el bilingüismo aymara-castellano entre niños y escolares es sólo una realidad en los sectores geográficos más altos, como el altiplano. En resumen, desde el punto de vista del conocimiento y la competencia lingüística, estamos en presencia de contextos sociales en que el bilingüismo aymara-castellano está presente en cierta proporción (poco más de un tercio de los casos, un $35,5 \%$ de los que declaran competencia en aymara $)^{4}$, pero donde prevalecen tipos de bilingüismo subordinados respecto del castellano. El monolingüismo castellano está ampliamente distribuido y es mayoritario. Es posible asumir que esta situación se relaciona con las tendencias de desplazamiento y reemplazo del aymara, que se observan en la región.

3.4. El aprendizaje del aymara y del castellano. Como es sabido, la familia y la comunidad local son las dos instituciones más importantes de transmisión y reproducción de las lenguas indígenas. Sólo recientemente dichas lenguas han empezado a ser integradas en la enseñanza escolar a nivel básico en el marco de la EIB, sin que sea posible aún evaluar el posible impacto en su mantención o revitalización. Un antecedente fundamental es el hecho de que el castellano tiene una larga presencia en las comunidades de valles precordilleranos, donde ya se había extendido consistentemente a finales del siglo XIX. En el altiplano, se debe esperar el arribo de las escuelas públicas (a partir de 1930) para su expansión masiva (González 2002). Esto significa que la incorporación del castellano en la zona aymara tiene casi un siglo, (o, al menos, siete décadas, según las áreas ecológicas) hasta llegar a convertirse en la lengua dominante. Esta realidad general se manifiesta en la información recogida a través de la encuesta.

Entre aquellos que declaran competencia en lengua aymara, aparece una situación bastante heterogénea en el aprendizaje de la primera lengua, que puede ser el castellano, el aymara o ambos simultáneamente. La mayor parte (un 44,8\%), declara haber aprendido simultáneamente la lengua aymara y el castellano. Un 31,3\% aprende primero el castellano y luego el aymara, mientras que la situación inversa sólo se presenta en un 23,9\% de los casos. Siguiendo la tendencia de abandono hacia los sectores ubicados a menor altitud, el mayor número de personas que declaran tener al aymara como primera lengua se encuentran en el altiplano, con un porcentaje $(83,9 \%)$ que considera también a aquellas personas que lo aprenden simultáneamente con el castellano. Lo inverso ocurre en las zonas bajas.

La distribución del aprendizaje de la primera lengua descrita indica un rápido proceso de reemplazo del aymara por el castellano, que está aprendiéndose de manera masiva y temprana en todos los hogares indígenas de la zona rural de la región. Ya casi no existen niños que aprendan primero el aymara y después el castellano. El aymara se aprende hoy junto o con posterioridad al castellano.

De acuerdo a la información etnográfica con que contamos, es posible identificar como condiciones favorables para la transmisión intergeneracional del aymara el haber nacido y/o vivir en localidades de los sectores altoandinos, donde históricamente la lengua aymara ha sufrido menos presión por el castellano, y el tener posibilidades de interacción frecuente con adultos mayores que empleen el aymara regularmente y en circunstancias cotidianas. Se podría conjeturar que los procesos de deslocalización de la población andina atentan contra lo anterior, llevando a la fragmentación de las redes de relaciones familiares y

\footnotetext{
${ }^{4}$ Desestimamos por improbables las dos declaraciones de competencia nula en castellano por corresponder, seguramente, a un grado avanzado de bilingüismo subordinado del castellano.
} 
crianza de los niños. La responsabilidad en el uso y enseñanza de la lengua descansa la mayor parte del tiempo en la familia nuclear, la que se encuentra con mucha frecuencia fuera de las localidades rurales, mientras las formas de agrupación familiar más amplias están dispersas residencialmente. Por ende, no se da ninguna de las dos condiciones recién identificadas: la lengua castellana domina ampliamente las interacciones sociales al interior de la localidad de residencia y no se produce una interacción continua y permanente con los "mayores", como los denominan los aymaras.

La observación en terreno en las localidades aymaras del interior apoyan la suposición de que, además de los factores recién descritos, la dinámica intrafamiliar actual tiende a reforzar el aprendizaje y uso del castellano: los padres promueven voluntaria o involuntariamente la autorrepresión del uso de la lengua aymara; y, por hábito o decisión, se comunican, cotidiana o frecuentemente, en su lengua con otras personas de la localidad y con sus hijos. Estos son aspectos de enorme importancia si se considera el rol que los progenitores tienen en la formación lingüística de sus vástagos, lo que se observa en el hecho de que la gran mayoría de los encuestados que manejan el aymara lo aprendieron de los padres. La comunidad constituye un ambiente favorable para mantener y, eventualmente, ampliar los conocimientos lingüísticos, pero es indispensable la acción familiar, ya que es en su seno donde se aprende la lengua aymara. Finalmente, además, o de manera supletoria a los padres, parece necesario o muy ventajoso contar con parientes cercanos, ojalá adultos mayores, que la hablen regular y diariamente. Lamentablemente, mientras los adultos mayores aymara hablantes residen en un importante número en las localidades rurales, la mayor parte de los niños vive y estudia en establecimientos urbanos, salvo durante breves periodos de tiempo en el año en que retornan a sus comunidades de origen.

En cuanto al uso de la lengua indígena en los contextos institucionales, este es muy bajo o casi inexistente. Por ejemplo, el 78,2\% de los casos señala que el aymara no es empleado (no se escuchaba o no se usaba) en la escuela de la comunidad escolar de referencia. Lo mismo ocurre en otros espacios de interacción local, sobre todo cuando intervienen agentes estatales que, en su casi totalidad, ignoran dicha lengua.

3.5. Los usos del aymara y del castellano en la región de Tarapacá. Los antecedentes sociolingüísticos expuestos proporcionan una imagen de crisis de la lengua aymara. Las condiciones y características del uso del aymara y del castellano pueden entregar antecedentes para comprobar o rechazar esta aseveración.

Un primer aspecto a revisar es la segmentación social del uso, observable a través del grado de contacto de la población del área estudiada con la lengua aymara. Si se observa lo que ocurre con las personas que no saben aymara, la mayor parte (un 71,3\%) no ha escuchado hablar en esta lengua en más de un mes. En concordancia con lo ya analizado, los porcentajes aumentan a medida que se avanza hacia los sectores geográficos más bajos. Es decir, estas personas no sólo no hablan el aymara sino que, además, lo escuchan con poca frecuencia. Para este fenómeno se pueden plantear las siguientes explicaciones: se trata de comunidades donde la lengua se emplea poco o nada; o bien, de localidades que presentan segmentaciones internas que inciden en un uso socialmente diferenciado del aymara. Partiendo de la tendencia general hacia la disminución del uso de la lengua indígena, es pertinente recordar la separación social existente entre los inmigrantes con mayor dominio del aymara y residentes originarios sin competencia en esta lengua, situación característica de los sectores de precordillera, valles bajos y oasis $^{5}$. Estos agregados de personas interactúan en castellano, la lengua predominante en estos sectores. El aymara se circunscribe a los espacios de interacción de quienes efectivamente hablan esta lengua, provenientes de los sectores más altos.

En general, la lengua aymara se habla con baja frecuencia entre quienes la manejan. Sólo poco más de un tercio (un 37,3\%) la emplea diariamente, en tanto que el resto la usa ocasionalmente (30,5\%) nunca o rara vez $(32,2 \%)$. Se debe insistir en el hecho de que, en el mundo andino actual, en los ámbitos en que deja de utilizarse el aymara, el castellano se instala como código de comunicación en su reemplazo.

Tabla 5

Frecuencia de uso de lengua aymara por quienes declaran competencia con ella según zonificaciones andinas de la Región de Tarapacá

\footnotetext{
5 Para realidades sociales con bilingüismo o multilingüismo, el concepto de dominio designa esferas de actividad, de interacción social y de comunicación con diferentes delimitaciones de tiempo y espacio social; modalidades de relación e interacción, valoraciones y posiciones características por parte de los actores involucrados. A estos dominios del tipo como trabajo, hogar, familia, comunidad, deporte, religiosidad, etc. pueden corresponder a opciones socialmente confirmadas de uso de una u otra lengua o de dos o más indistintamente, en la medida en que converjan tipos de interlocutores en los lugares y momentos apropiados, y respecto de campos de significado también determinados. Esta concurrencia define el grado de congruencia de la interacción en los dominios (Romaine, 1996: 62-64). Una introducción puede encontrarse en Holmes (1992: 23-28).
} 


\begin{tabular}{|c|c|c|c|c|c|}
\hline & \multicolumn{4}{|c|}{ Frecuencia de uso } & \multirow[b]{2}{*}{ Total } \\
\hline & A diario & $\begin{array}{c}\text { Ocasionalme } \\
\text { nte }\end{array}$ & Rara vez & Nunca & \\
\hline Altiplano & 34 & 18 & $\square 6$ & $\square 1$ & $\square 59 \square \square 50,0 \%$ \\
\hline Precordillera andina & $\square 4$ & 12 & 16 & $\square 2$ & $\square 34 \square \square 28,8 \%$ \\
\hline Valles bajos, oasis y pampa & $\square 6$ & $\square 6$ & $\square 7$ & $\square 6$ & $\square 25 \square \square 21,2 \%$ \\
\hline Total & $44 \square \square 37,3 \%$ & $36 \square \square 30,5 \%$ & $29 \square \square 24,6 \%$ & $\square 9 \square \square 7,6 \%$ & $118 \square \square 100 \%$ \\
\hline
\end{tabular}

Fuente: Encuesta contexto sociolingüístico de comunidades escolares indígenas, 2003.

La frecuencia de uso del aymara depende de espacios sociales diferenciados según la gradiente altitudinal andina. En el altiplano es usada de manera más frecuente porque existen condiciones favorables para su uso. En el otro extremo, en los valles bajos, los oasis y la pampa existen menos personas que la conocen y es muy poco u ocasionalmente empleada. En las zonas de precordillera, si bien existen más hablantes que en los sectores más bajos, su empleo es también ocasional o poco frecuente. Tanto en los valles precordilleranos como en los sectores más bajos, la posibilidad de uso del aymara depende de los aportes altoandinos. La presencia de la lengua aymara no está, pues, relacionada con la existencia de un núcleo de hablantes originarios, sino con la afluencia de inmigrantes provenientes del altiplano chileno y boliviano.

La estructuración social del uso del aymara adquiere así una fisonomía característica: en las comunas altoandinas, los grupos sociales y la comunidad de hablantes indígenas son una misma cosa. En cambio, en las zonas de precordillera, valles bajos y oasis del desierto, los agregados de hablantes están diferenciados social y étnicamente entre quienes tienen alguna competencia o hablan el aymara y aquellos (aymaras o no) que no la hablan (oriundos de estos valles o descendientes de generaciones que ya lo perdieron). Los residentes de origen altiplánico, sea que se les considere un grupo definido o como segmentos de redes sociales particulares, tienen una especificidad reconocida dentro de las comunidades locales de esta zona, que los denominan "los del altiplano", "paisanos" o "indios", todas ellas categorías discriminadoras que marcan simbólicamente las diferencias con la población local. Entre unos y otros se generan distancias sociales normalmente no explicitadas, reproduciendo un juego de sobreentendidos sociales. La lengua aymara queda, así, socialmente confinada a los segmentos "andinos", pero su uso no es coextensivo a la totalidad de la comunidad, cuyo código lingüístico es el castellano. El aymara tenderá a emplearse sólo en los espacios sociales propios de los inmigrantes y su frecuencia de uso dependerá de las circunstancias internas y los ambientes sociales más amplios en que viven. La información etnográfica disponible hace suponer que, aún en esos espacios internos, el uso disminuye ostensiblemente en relación con lo que ocurre en las comunidades altoandinas de las que provienen estos sujetos, lo que parece indicar que no basta tener dominio de la lengua y que existan ciertas condiciones sociales favorables para su uso, sino que, además, deben intervenir otros factores, tanto de contexto como psicosociales.

La manifestación del aymara en ciertos espacios sociales y momentos remite a los usos y contextos de uso de esta lengua. Se debería esperar que estos contextos sean principalmente internos o intraétnicos y que los usos sean también relativamente específicos y especializados.

Tabla 6

Uso de la lengua aymara en la interacción lingüística por parte de quienes indican competencia en esa lengua según contextos de interacción social en la Región de Tarapacá

\begin{tabular}{|l|l|l|}
\hline Contextos de uso & Uso hablado del aymara & Total $\square \square \square \%$ \\
\hline
\end{tabular}




\begin{tabular}{|c|c|c|c|}
\hline & Sí $\square \square \square \square$ & No $\square \square \square \square \%$ & \\
\hline - Con la familia y familiares & $\square \square 91 \square \square 72,2$ & $\square \square 35 \square \square 27,8$ & $\square 126 \square \square 100$ \\
\hline - En la casa (hogar) & $\square \square 87 \square \square 69,0$ & $\square \square 39 \square \square 31,0$ & $\square 126 \square \square 100$ \\
\hline - En las actividades agropecuarias & $\square \square 85 \square \square 67,5$ & $\square \square 41 \square \square 32,5$ & $\square 126 \square \square 100$ \\
\hline - En la calle con otros indígenas & $\square \square 81 \square \square 65,3$ & $\square \square 43 \square \square 34,7$ & $\square 124 \square \square 100$ \\
\hline - Con vecinos indígenas & $\square \square 77 \square \square 61,1$ & $\square \square 49 \square \square 38,9$ & $\square 126 \square \square 100$ \\
\hline - En reuniones de la comunidad & $\square \square 60 \square \square 47,6$ & $\square \square 66 \square \square 52,4$ & $\square 126 \square \square 100$ \\
\hline - En buses rurales con otros hablantes & $\square \square 52 \square \square 41,3$ & $\square \square 74 \square \square 58,7$ & $\square 126 \square \square 100$ \\
\hline - En reuniones escolares & $\square \square 27 \square \square 21,8$ & $\square \square 97 \square \square 78,2$ & $\square 124 \square \square 100$ \\
\hline - Con autoridades y servicios públicos en la ciudad & $\square \square 19 \square \square 15,1$ & $\square 107 \square \square 84,9$ & $\square 126 \square \square 100$ \\
\hline
\end{tabular}

Fuente: Encuesta contexto sociolingüístico de comunidades escolares indígenas, 2003.

Las situaciones sociales antes señaladas se pueden definir como una combinación específica de actores en interacción en un espacio y un tiempo determinados, y cuya comunicación puede o no realizarse en lengua nativa. Las oportunidades de empleo del aymara se organizan según dos principios: el ámbito social (público/privado) y el carácter étnico (intra/extraétnico). Mientras más privada e intraétnica sea la situación social, más plausible es que los actores involucrados opten por el aymara. A su vez, mientras más público y externo sea el ambiente, más utilizan el castellano. En la percepción de los entrevistados, son precisamente espacios como el hogar, las relaciones con familiares o las actividades agrarias los que se asocian con la lengua aymara. En cambio, las reuniones comunitarias, la interacción en viajes, el medio escolar, los vínculos con la burocracia estatal, y relaciones con el mercado, se asocian con el castellano.

Estas reglas generales sufren diversas variaciones en la práctica. Aun en el seno de los espacios étnicos, el uso del castellano puede constituir una necesidad cuando alguno de los partícipes de la interacción no sabe hablar aymara o, aún cuando sepa, se niegue a interactuar en dicha lengua por una cuestión de desempeño o hábito de evitarla. En estos casos se pueden dar dos fórmulas distintas de solución: la alternancia entre el aymara y el castellano o el uso exclusivo del castellano, opción que tiene la enorme ventaja de ser conocida por todos y no presentar rechazo social. En el otro extremo del continuo, existen dificultades prácticas que limitan el uso del aymara: los docentes en los medios escolares no saben expresarse en lengua aymara y, en muchos casos, se molestan si ésta es usada en su presencia; los funcionarios públicos y las autoridades tienen aún menos oportunidades e interés de aprender el aymara, por lo que no existe con ellos otra posibilidad que la de comunicarse exclusivamente en castellano. En situaciones menos definidas (como encuentros en calles urbanas) tiende a imponerse el castellano, pero tampoco queda forzosamente excluido el aymara; dependerá de quienes entablan el diálogo, de si existe alguna certidumbre acerca de las capacidades lingüísticas de los interactuantes y si se da una expectativa recíproca o disposición al diálogo en esta lengua.

Este es, en líneas gruesas, el panorama actual de la organización social del uso del aymara en distintos contextos de interacción. ¿Nos encontramos ante una situación de diglosia? ${ }^{6} \mathrm{Si}$ por ella se entiende la existencia de una lengua socialmente subordinada a otra, entonces se tendría que aceptar que

\footnotetext{
${ }^{6}$ Preferimos emplear el concepto en su sentido original, propuesto por Ferguson (1959), según el cual en situaciones de bi- o multilingüismo -o de variación dialectal- existe diglosia cuando hay especialización, más o menos estable, de funciones de esas lenguas o variedades. La diglosia clásica es la de una lengua "culta" con funciones distintas a las de una "baja" o popular empleada para otros fines. Las situaciones de diglosia suelen estar asociadas a condiciones de dominación social y política, pero no siempre se da esta relación. El caso chileno lo ejemplifica bien, en la medida que puede darse una minorización social y lingüística de las lenguas indígenas sin que haya diglosia. El estudio de la subordinación, minorización, posición económica y sociopolítica del grupo portador y la relación de todo ello con una lengua o variedad debe analizarse de manera más general, donde los estados de diglosia representan sólo un resultado posible. Un desarrollo importante del concepto se encuentra en Fishman (1988: 120-133), y es rediscutido por Fasold (1996:71-108).
} 
en este caso hay diglosia. Sin embargo, si el concepto se aplica en su sentido original, como una situación de coexistencia de lenguas con funciones diferenciadas e institucionalizadas, tendríamos que suscribir que no (ver también: Vergara y Godoy 2003: 88). La lengua aymara sería hoy prescindible o reemplazable por el castellano prácticamente para casi todos los fines.

3.6. El desplazamiento de la lengua aymara por el castellano. Como hemos señalado, en la actualidad los habitantes del área de comunidades indígenas de Tarapacá son principalmente castellanohablantes. Sólo un 35,5\% de los entrevistados declararon poseer algún grado de competencia en lenguas indígenas y, entre aquellos que se reconocen como aymaras, poco más de la mitad (un 51,5\%) reconoce niveles de competencia activa buena o muy buena en su lengua. Esto significa que poco menos de un quinto $(17,4 \%)$ de los residentes en las comunidades estudiadas tiene un manejo fluido de ella. Estos datos corresponden, además, a la población rural, el área que se podría esperar fuese la menos afectada por el desplazamiento lingüístico ${ }^{7}$. Los cambios, pero también las persistencias, deben encontrar cabida en una explicación de la dinámica de la lengua indígena regional.

La vigencia histórica del aymara dentro del espacio andino es muy variable. El altiplano y la alta cordillera -y, junto con esta zona, las regiones limítrofes bolivianas- se presentan como los grandes reservorios de conservación de la lengua aymara, a pesar de los rápidos cambios que han tenido lugar en ellos. Los valles bajos, oasis y pampa, al igual que los centros urbanos regionales, donde llegan hablantes aymaras desde las tierras altas y Bolivia, son sectores de predominancia del castellano. El área de valles altos o precordillera presenta una situación intermedia. En esta zona se mantuvieron hasta hace algunas décadas, algunos hablantes aymaras y ha sido también el blanco de importantes migraciones. La tabla que se presenta a continuación muestra el conocimiento declarado del aymara por parte de los antecesores de los actuales miembros de las comunidades estudiadas que declaran competencia en lengua aymara y la importancia que en esa vigencia tiene la proveniencia desde el espacio altoandino. Entre sus padres, un $61,5 \%$ (bilingüe) habría hablado o hablaría aymara y castellano, un 18,0\% (monolingüe) sólo aymara y un 20,5\% (monolingüe) sólo castellano. En el caso de las madres, un 52,9\% hablaba aymara y castellano, un $33,1 \%$ sólo aymara ${ }^{8}$ y un $14,0 \%$ sólo castellano. A su vez, la información respecto de los abuelos muestra un alto grado de vigencia del aymara (y una menor presencia del castellano), y una clara relación de esta vigencia con orígenes altoandinos.

Tabla 7

Secuencias de cambio lingüístico generacional en comunidades indígenas de la Región de Tarapacá según el área de nacimiento de los que declaran competencia en aymara

\begin{tabular}{|c|c|c|c|c|c|c|}
\hline & & \multicolumn{4}{|c|}{ Area de nacimiento } & \multirow{2}{*}{ Total } \\
\hline & & Altiplano & $\begin{array}{l}\text { Valles } \\
\text { altos }\end{array}$ & $\begin{array}{l}\text { Valles bajos, } \\
\text { oasis y pampa }\end{array}$ & Otros sitios & \\
\hline \multirow{4}{*}{$\begin{array}{l}\text { Lengua que } \\
\text { habla(ba) } \\
\text { el padre }\end{array}$} & Aymara & 19 & $\square 1$ & $\square 0$ & $\square 2 \square$ (Bolivia) & $22 \quad 18,0 \%$ \\
\hline & Castellano & $\square 5$ & $\square 8$ & $\square 3$ & $\square 9$ & $25 \quad 20,5 \%$ \\
\hline & Castellano-aymara & 54 & 10 & $\square 2$ & $\square 9 \square(7 \square$ Bolivia) & $75 \square 61,5 \%$ \\
\hline & & $78 \square 63,9 \%$ & $\begin{array}{l}19 \square 15,6 \\
\%\end{array}$ & $5 \square 4,1 \%$ & $20-16,4 \%$ & $122 \quad 100 \%$ \\
\hline
\end{tabular}

\footnotetext{
7 El concepto de "desplazamiento" se refiere al proceso por el cual una lengua o variedad lingüística es reemplazada por otra. Los factores concurrentes en este resultado pueden ser múltiples: políticas lingüísticas, cambios religiosos, opresión cultural, migraciones, etc. La duración del proceso puede también ser muy disímil de caso a caso. La inestabilidad en el bilingüismo, la competencia entre lenguas y los fenómenos de desplazamiento son muy comunes en la dinámica de las lenguas en cualquier parte del mundo. La tendencia general durante el siglo XIX, y sobre todo en el XX, es a la expansión de lenguas y variedades constituidas en nacionales y oficiales. En las últimas décadas tiene lugar la expansión de lenguas globales o generales a grandes regiones del planeta. Es común en la dinámica de las lenguas indígenas en Chile y Latinoamérica una transición desde el monolingüismo indígena, pasando por un bilingüismo sin diglosia con competencia por dominios, hasta la desaparición de la lengua vernácula. Adelaar (1991: 83-138) hace una caracterización del panorama sudamericano actual. Para una discusión más general, véase: Crystal (2001).

${ }^{8}$ Lo que concuerda con el antecedente de que es entre ellas donde se presenta la posesión de mayor competencia en lengua aymara (Harmelink 1985).
} 


\begin{tabular}{|c|c|c|c|c|c|c|}
\hline \multirow{4}{*}{$\begin{array}{l}\text { Lengua que } \\
\text { habla(ba) } \\
\text { la madre }\end{array}$} & Aymara & 31 & $\square 5$ & 0 & $\square 4 \square$ (Bolivia) & $40 \square 33,1 \%$ \\
\hline & Castellano & $\square 4$ & $\square 5$ & 2 & $\square 6$ & $17 \quad 14,0 \%$ \\
\hline & Castellano-aymara & 42 & 11 & 1 & $10 \square(7 \square$ Bolivia $)$ & $64 \quad 52,9 \%$ \\
\hline & & $77 \square 3,6 \%$ & $\begin{array}{l}21 \square 17,4 \\
\%\end{array}$ & $3 \square 2,5 \%$ & $20 \square 16,5 \%$ & $121 \quad 100 \%$ \\
\hline \multirow{4}{*}{$\begin{array}{l}\text { Lengua que } \\
\text { habla(ba) el } \\
\text { abuelo paterno }\end{array}$} & Aymara & 46 & $\square 5$ & 0 & $\square 7 \square$ (Bolivia) & $58 \square 57,4 \%$ \\
\hline & Castellano & $\square 0$ & $\square 2$ & 3 & $\square 3$ & $8,7,9 \%$ \\
\hline & Castellano-aymara & 20 & $\square 8$ & 2 & $\square 5 \square(3 \square$ Bolivia) & $35 \square 34,7 \%$ \\
\hline & & $66 \square 65,3 \%$ & $15 \square 14,9 \%$ & $5 \square 5,0 \%$ & $15 \square 14,8 \%$ & $101 \square 100 \%$ \\
\hline \multirow{4}{*}{$\begin{array}{l}\text { Lengua que } \\
\text { habla(ba) la } \\
\text { abuela paterna }\end{array}$} & Aymara & 48 & $\square 5$ & 1 & $\square 7 \square$ (Bolivia) & $61 \square 61,6 \%$ \\
\hline & Castellano & $\square 0$ & $\square 1$ & 2 & $\square 3$ & $6 \quad 6,1 \%$ \\
\hline & Castellano-aymara & 16 & $\square 9$ & 2 & $\square 5 \square(3 \square$ Bolivia) & $32 \square 32,3 \%$ \\
\hline & & $64 \square 64,6 \%$ & $\begin{array}{l}15 \square 15,2 \\
\%\end{array}$ & $5 \square 5,1 \%$ & $15-15,1 \%$ & $99 \square 100 \%$ \\
\hline \multirow{4}{*}{$\begin{array}{l}\text { Lengua que } \\
\text { habla(ba) el } \\
\text { abuelo materno }\end{array}$} & Aymara & 47 & $\square 6$ & 0 & $\square 6 \square$ (Bolivia) & $59 \quad 61,5 \%$ \\
\hline & Castellano & $\square 1$ & $\square 0$ & 3 & $\square 5$ & $9 \quad 9,4 \%$ \\
\hline & Castellano-aymara & 14 & $\square 9$ & 1 & $\square 4 \square(3 \square$ Bolivia) & $28 \square 29,1 \%$ \\
\hline & & $62 \square 64,6 \%$ & $\begin{array}{l}15 \square 15,6 \\
\%\end{array}$ & $4 \llbracket 4,2 \%$ & $1515,6 \%$ & $96 \square 100 \%$ \\
\hline \multirow{4}{*}{$\begin{array}{l}\text { Lengua que } \\
\text { habla(ba) la } \\
\text { abuela materna }\end{array}$} & Aymara & 52 & $\square 9$ & 0 & $\square 7 \square$ (Bolivia) & $68 \quad 68,0 \%$ \\
\hline & Castellano & $\square 0$ & $\square 0$ & 3 & $\square 5$ & $8 \quad 8,0 \%$ \\
\hline & Castellano-aymara & 13 & $\square 6$ & 1 & $\square 4 \square(3 \square$ Bolivia) & $24 \quad 24,0 \%$ \\
\hline & & $65 \square 65,0 \%$ & $15 \square 15,0 \%$ & $4 \square 4,0 \%$ & $16 \square 16,0 \%$ & $100 \square 100 \%$ \\
\hline
\end{tabular}

Fuente: Elaboración propia con base en datos de encuesta sociolingüística, 2003.

La vigencia de la lengua aymara en las zonas bajas se explica por migraciones de individuos y familias de zonas aymarófonas durante las últimas décadas, puesto que allí el aymara había sido desplazado tempranamente por el castellano (Gundermann 1997). La nueva distribución espacial no se puede asociar con la estabilización y expansión del número de hablantes y, menos aún, con una mantención del bilingüismo. Actualmente, se presenta la paradójica y, a la vez, problemática situación de que hay proporciones cada vez menores de hablantes respecto del total de la población indígena, distribuidos ampliamente en la región, inclusive en sectores urbanos. Todo ello muestra la relevancia de la dimensión espacial y de los procesos migratorios en la dinámica sociolingüística del aymara. En efecto, su desplazamiento se corresponde con el desplazamiento espacial de las fronteras étnicas.

Según la información histórica disponible, hasta la primera mitad del siglo XIX, la lengua aymara se extendía a lo largo de todo el espacio andino, incluidas las comunidades de "indios" ubicadas en los valles bajos y en los centros mineros cercanos a Iquique donde laboraban peones aymaras (Gundermann 1997). El aymara era la lengua que presentaba la más amplia distribución y el mayor contingente de hablantes en toda la región, dado que los indígenas conformaban el grueso de la población regional. A partir de entonces, se inicia un proceso de agudos cambios. Muchos habitantes de los valles bajos y medios se empiezan a definir como no indígenas y se da inicio a una dinámica de diferenciación interna y 
redefinición de las fronteras étnicas en la región. Junto con ello, empieza un sostenido retroceso de la lengua aymara en un doble sentido: disminuye el número de hablantes por el avance del castellano en la población de los sectores bajos y su espacio de distribución se va limitando paulatinamente a las tierras altas. Ya a principios del siglo XX, la lengua aymara era usada extensivamente sólo en la precordillera alta y el altiplano, trasformándose en el área que será identificada por el resto de la sociedad regional como la zona de los "indios", poniendo en evidencia la relación entre esta categoría y el conocimiento de la lengua aymara (Gundermann 1997 y 2001). Dado que durante la segunda mitad del S. XIX y prácticamente en todo el S. XX, la denominación de "indio" fue sinónimo de una categoría social inferior y de una condición cultural atrasada, de ello no podía resultar sino la pérdida de su lengua. Los efectos de esta valoración negativa todavía están presentes, aunque hoy en día se busque revertirla a través de una política pública de reconocimiento étnico y se evidencie un cambio favorable hacia el respeto de las culturas indígenas en distintos sectores de la sociedad chilena.

Durante todo el siglo XX, la cultura y lengua aymaras sufrieron el poderoso impacto del Estado chileno en la Región, principalmente a través del desarrollo de obras públicas, la expansión del sistema escolar y la conscripción militar. La apertura de caminos y otros programas de inversión en infraestructura aceleran la integración económica y política de las zonas interiores a los centros regionales; a través de la escuela se difunden la cultura nacional y el uso del castellano; el servicio militar incentiva la adhesión a los valores nacionales y proporciona nuevas experiencias migratorias a las nuevas generaciones. La intervención del Estado y sus agentes produjo una asimilación cultural y desplazamiento lingüístico a favor del castellano.

La acción del mercado, unida a la del Estado, termina por abrir las sociedades andinas hacia el exterior. La monetarización y mercantilización de sus economías campesinas, la crisis entre población y recursos que provoca el sostenido aumento demográfico, la apropiación de instrumentos educacionales y lingüísticos, la creación y mejoramiento de las vías de comunicación y otros factores favorecen la integración de las comunidades con la Región. Todo esto implica un incremento exponencial de la movilidad de las personas y de las migraciones. En este contexto, los conocimientos, instrumentos y códigos de comunicación no pueden ser otros que los provistos por la cultura nacional y la lengua castellana. Conscientes de ello, las propias comunidades andinas tomaron un rol activo en favorecer su integración o regionalización, demandando del Estado la instalación de escuelas y el aprendizaje del castellano (González 2002).

\section{CONCLUSIONES}

El análisis anterior muestra que la mayor parte de los habitantes de la zona rural donde existe la más densa concentración de personas de origen aymara en la Región de Tarapacá son castellano-hablantes; sólo poco menos de un quinto del total de individuos que vive en este espacio tiene un manejo fluido del aymara. Si se considera únicamente a aquellos que se autorreconocen como pertenecientes a este pueblo, un poco más de la mitad de ellos declara tener un nivel de competencia eficiente en su lengua.

La distribución del conocimiento y uso del aymara dentro de este espacio no es homogénea, presentando importantes variaciones según sectores sociogeográficos. La cantidad de aymara-hablantes y la frecuencia de uso de esta lengua disminuyen siguiendo una gradiente altitudinal. En el altiplano es hablada con mayor frecuencia porque existen mejores condiciones sociales y lingüísticas favorables. En el otro extremo se ubican los valles bajos, los oasis y la pampa donde existen menos personas que la conocen y es empleada muy poco u ocasionalmente. En las zonas de precordillera encontramos una situación intermedia, ya que si bien existen más hablantes que en los sectores más bajos, el empleo es también ocasional o poco frecuente.

También existen diferencias en el manejo de la lengua según los contextos de uso. El aymara tiende a emplearse mayormente en ámbitos privados e intraétnicos, mientras que en los espacios públicos e interétnicos predomina casi exclusivamente el castellano. La lengua aymara se sigue usando al interior de los hogares, en las relaciones con familiares o en las actividades económicas y religiosas tradicionales. En las reuniones comunitarias, en los viajes, en el medio escolar, en los vínculos con funcionarios públicos y en muchas de las relaciones con el mercado y la sociedad la comunicación se realiza en castellano. Sin embargo, esta situación es válida solamente para los sectores de altura. En las zonas más bajas, en cambio, se mantiene solamente en los segmentos de personas que llegan desde el altiplano chileno y boliviano, puesto que los habitantes originarios dejaron de hablar la lengua hace varias décadas e incluso varias generaciones.

El uso diferenciado del aymara y el castellano según el contexto de que se trate ha llevado a 
sostener que existe entre ellas una diglosia institucionalizada. Los resultados de este trabajo indican que esto no es efectivo. Por otro lado, el bilingüismo ha ido retrocediendo y los usos y funciones de cada lengua no están claramente delimitados y estabilizados. En la actualidad, incluso en los espacios que se podrían considerar más tradicionales, se emplea extensivamente el castellano o se lo alterna con el aymara.

Desde una perspectiva más amplia, el avance del castellano y el retroceso del aymara no pueden explicarse únicamente por las posibilidades y frecuencias de la interacción social, sino, en términos más amplios y en una perspectiva histórica, en relación con la estructura y tipo de relaciones sociales que se establecen entre grupos que se forman de una manera diferenciada; por un lado, los habitantes de los sectores más bajos que, ya a mediados del S. XIX, iniciaron un proceso de integración y de relativo abandono de la cultura y lengua aymaras; por otro, los habitantes de los sectores más altos que empiezan a ser tratados por los primeros como "indios", en una clara expresión de discriminación.

Las diferencias según estratos sociogeográficos son muy importantes para comprender la distribución y los cambios de la lengua aymara en la región. En los sectores más bajos el aymara fue desplazado tempranamente por el castellano, por lo que la presencia actual de esta lengua en ellos se explica por la presencia de individuos y familias que han migrado desde zonas aymarófonas. En la actualidad, las fronteras lingüísticas se han redefinido de forma contradictoria; si bien los aymaras se han dispersado por toda la Región y las presiones para el ocultamiento y abandono de la lengua han disminuido, las condiciones sociales dominantes no favorecen su mantención y recuperación. La cultura y lengua aymaras son apreciadas por muchos como algo del pasado o como un componente que se puede mantener en la medida que no obstaculice la integración a la sociedad mayor. La lengua aymara puede persistir en ámbitos internos a la vida social familiar y comunitaria, pero no es funcional a la regionalización de la comunidad aymara.

Una cuestión fundamental, no resuelta en modo alguno, es la situación de la lengua aymara en las ciudades y pueblos, donde hoy reside la mayor parte de su población. A falta de estudios sociolingüísticos sobre la materia, sólo pueden plantearse algunas inferencias. Primero, en el medio urbano se dan nuevas posibilidades de mejoramiento social, de las que los migrantes del interior hacen un amplio uso, como el acceso a vivienda o a educación media y superior. Allí se redefine también la relación entre las zonas interiores y los centros urbanos costeros. Los límites se han vuelto borrosos; muchas familias campesinas tienen también residencia y ocupaciones urbanas; un cierto número de indígenas que vive en las ciudades sigue manteniendo actividades agropecuarias; aunque el campo tiende a vaciarse en época escolar e invernal, en época de vacaciones las familias se trasladan a sus comunidades de origen: muchos vuelven periódicamente a regar chacras, etc. (González 1996 y 1997; Gundermann 2001). Por último, las migraciones y las complejas redes de movilidad de las personas tienen consecuencias para el uso y continuidad de la lengua aymara. Las primeras oleadas migratorias a las ciudades correspondieron a grupos no aymarófonos, provenientes de los sectores de valles donde se había perdido casi completamente la lengua, mientras la segunda oleada, la más reciente, corresponde a contingentes de hablantes aymaras. Es posible sostener, entonces, que si bien en las últimas tres décadas la lengua aymara se ha extendido a lo largo de toda la Región, los actuales espacios sociales de inserción presentan oportunidades limitadas y condiciones restrictivas para su uso, que se reducen básicamente a los contextos étnicos de interacción (familia, reuniones con parientes, lugares de trabajo con alta concurrencia de personas del mismo origen). Sin embargo, y dado el bilingüismo subordinado del aymara, el bajo porcentaje de competencia activo en la propia lengua y la masificación del uso del castellano, incluso en los eventos de interacción intraétnica, la lengua indígena parecería haber dejado de ser un instrumento de comunicación empleado extensivamente. Puede usarse, y se usa con alguna frecuencia o regularidad en un cierto número de hogares o en la relación entre algunas personas, pero claramente no es una lengua de uso intensivo. En los medios urbanos, el empleo de esta lengua sería, por tanto, muy restringido y se confinaría a ámbitos muy circunscritos.

\section{OBRAS CITADAS}

Adelaar, Willem. 2000. "El problema de las lenguas en peligro. América del Sur". Lenguas en Peligro. R. Hobins, E. Uhlenbeck y B. Garza (eds.). México: INAH.

Albó, Xavier. 2000. “Aymaras entre Bolivia, Perú y Chile”. Estudios Atacameños 19: 43-73.

Crystal, David. 2001. La muerte de las lenguas. Madrid: Cambridge University Press.

Danemann, Manuel y Alba Valencia. 1989. Grupos aborígenes chilenos. Su situación actual y distribución territorial. Santiago: Universidad de Santiago de Chile. 
Fasold, Ralph. 1996. La sociolingüística de la sociedad. Madrid: Visor Libros.

Ferguson, Charles. 1959. "Diglossia”. Word XV: 325-340.

Fishman, Joshua. 1988. Sociología del lenguaje. Madrid: Catédra.

González, Héctor. 1996. Características de la migración campo ciudad entre los aymaras del norte grande de Chile. Arica: Taller de Estudios Andinos, Serie Documentos de Trabajo.

— 1997. "La inserción económica de los migrantes aymaras en la ciudad: el trabajo como empresa familiar y la reproducción cultural”. Actas del Segundo Congreso Chileno de Antropología. Santiago, 567-579.

González, Sergio. 2002. Chilenizando a Tunupa. La escuela pública en el Tarapacá andino, 1880-1990, DIBAM, Santiago.

Gundermann, Hans. 1994. “Cuántos hablan en Chile la lengua aymara?”. Revista de Lingüística Teórica y Aplicada 32: 125-139.

—. 1997. "Acerca de cómo los aymaras aprendieron el castellano (terminando por olvidar el aymara)". Estudios Atacameños 12: 97-113.

- 2001. Comunidad, sociedad andina y procesos socio-históricos en el norte de Chile. Tesis Doctoral, Centro de Estudios Sociológicos, El Colegio de México, México, Ms.

Gundermann, Hans, Rolf Foerster y Jorge Iván Vergara. 2005. "Contar a los indígenas en Chile. Autoadscripción étnica en la experiencia censal de 1992 y 2002". Estudios Atacameños 31: 91-115.

Harmelink, Brian. 1985. Investigaciones lingüísticas en el altiplano chileno. Un estudio sobre la comunidad aymara chilena. Arica: Instituto Lingüístico de Verano, Universidad de Tarapacá, Ms.

Holmes, Janet. 1992. An Introduction to Sociolinguistics. Inglaterra: Longman Group.

Hymes, Dell. 1988. "Communicative Competence", en: Sociolinguistics. U. Ammon, N. Dittmar y K. Mathier (Eds). Berlín: De Gruyter, 219-229.

Instituto Nacional de Estadísticas (INE). 2002. Censo 2002. Resultados Población y Vivienda. Santiago: INE.

Rommaine, Suzanne. 1996. El lenguaje en la sociedad. Barcelona. Ariel Lingüística.

Salas, Adalberto. 1996. "Lenguas indígenas de Chile". Etnografía. Sociedades indígenas contemporáneas y su ideología, Hidalgo, Jorge y Schiappacasse, Virgilio (eds.). Santiago: Editorial Andrés Bello, 257-295.

Vergara, Jorge Iván y Luis Godoy. 2003. "Interculturalidad, educación y lenguas indígenas. Desafíos globales y experiencias regionales". Cultura, educación y paz en el marco de la integración subregional. Iquique: Ediciones Campus, Universidad Arturo Prat, 71-100.

Vergara, Jorge et al. 2005. Descripción del contexto sociolingüístico en comunidades indígenas de Chile. Santiago: MINEDUC-Programa EIB/Orígenes. 